\title{
And the Walls Come Tumbling Down: The Converging Destinies of the Rutgers University Libraries and the Center for Computer and Information Services
}

\author{
by Linda Langschied" \\ \& Gertrude J. Lewis
}

ON OCtOBER 16, 1990, THE FOLLOWING MANDATE WAS issued from the office of tile President of Rutgers UNTVERSITY...

"Complex interrelationships among print information, electronic data, resources, and telecommunications have opened enhanced possibilities for access to both information and communication for scholarly and management purposes. This sophisticated information and communications environment has, as a result, led to a convergence of many of the functions of libraries and computing services.... Bringing computing facilities and libraries under the same management will enable us to build on existing strengths, avoid duplication, and coordinate planning, thereby enabling us to improve service to users."

Now the directors of the academic and administrative computing centers report to the Associate Vice President for Information Services, who is also the Associate University Librarian for Technical and Automated Services. He reports to the Vice President for Information Services and the University Librarian.

IN THE BEGINNING....

Two decades ago, representatives from Rutgers and Princeton universities met at Firestone Library, Princeton, to discuss means for acquiring the 1970 Census of Population and Housing data. The result of that meeting was the formation of a group calling itself the PrincetonRutgers Census Data Project. A number of agreements were reached concerning costs, finances, billing for services, and procedures for acquiring data and software.

Three hundred reels of census data and a number of utilities to aid in accessing the data were purchased at that time. The census data was stored at the Princeton University Computer Center and upon request copies were made and housed at Rutgers University Center for Computer and Information Services (CCIS). Training seminars were made an integral part of the program. Funding for the Project came not only from the computer centers and libraries of the two universities, but also from some individual departments. Although not all contingencies were considered in the original agreement, the Princeton-Rutgers Census Data Project was founded in a spirit of cooperation and the belief that the primary objective was to make the 1970 census data available to members of the academic community as quickly and as economically as possible.

As the census data project developed, a "Census Packet" was sent to Rutgers libraries and key academic departments. Originally it was felt that interested people should go to the library first and not directly to CCIS. Library staff would help patrons to understand available census data in printed and magnetic tape form. At first, the census data tapes were stored at Princeton, and the Rutgers users paid for programming and computer time to Princeton. Thus began our road of cooperation between the CCIS and the University libraries that continues today.

THe CURRent St ATUS OF MACHINE-REadable Data FILES... Now the Rutgers branch of the Princeton-Rutgers Census Data Project houses its own data tapes and has been active in three major areas: education, consultation and data retrieval. To facilitate the use of census materials, the CCIS has published many technical documents for faculty, staff and students that deal with locating, accessing, and analyzing census data. On the reference shelves of the libraries, are publications created by the CCIS staff in which the researchers can locate the names and corresponding codes of the census geographic areas in New Jersey or look up the index of machine-readable data files available to the Rutgers community. Information on the data acquisitions are publicized in the bimonthly CCIS Newsletter.

However, census data is only a part of the extensive machine-readable data files (MRDF) collection services provided by the CCIS in conjunction with the libraries.

\section{The Roper Center}

The libraries and computer centers of both Rutgers and Princeton University participate in a joint membership with the Roper Center's International Survey Library Association (ISLA). The universities are entitled to the research services of searching the archives, producing tabulations of data analysis, and acquiring machinereadable data sets. As part of this venture, we also subscribe to the Public Opinion Location Library (POLL) Database. 
The Inter-university Consortium of Political And Social Research

Membership in the Inter-university Consortium of Political and Social Research (ICPSR) provides not only the acquisition of data and accompanying documentation, but also the opportunity to attend workshops in the ICPSR Summer Session. Over the years, the librarians, computer personnel, and academic researchers have attended these classes and brought information back to our researchers on ICPSR's expanding resources. When the CCIS orders a data set from ICPSR, we receive a magnetic tape and an accompanying codebook in hardcopy. The tape is stored at the computer center and is available to anyone on or off campus who has a computer account. The codebooks are shelved in the CCIS Computer Reference Center (CRC), which is a small reference room, open about eighteen hours a week.

\section{Data Base Advisory Committee}

As an increasing number of researchers discover the enormous volume of data produced which have intrinsic research and academic value, they realize that these data are unmanageable without the use of a computer. In 1976 through the coordination of the CCIS, the Political Science and Sociology departments, and the library, the responsibility of the handling of ICPSR and Roper machine-readable data was transferred to the CCIS. Although the Roper membership originated in the Sociology Department and the ICPSR membership started with the Political Science Department, the costs of these memberships come out of the library budget. The CCIS became responsible for the acquisition and maintenance of the various data sets. It was felt that a central clearing house for databases would eliminate duplicate purchases that had occurred. Under the CCIS, all communications from Census, ICPSR and Roper that might be of academic interest would be forwarded to the librarians, the appropriate department chairperson or representative.

A Data Base Advisory Committee was created to include participation with the various social science disciplines and with the libraries (again both Rutgers and Princeton universities) in order to determine general policies concerning acquisition and access. This committee meets periodically to keep up with the current activities in the field. As usage has expanded, representatives from other departments who wish to use the data can join the committee or participate as guests. The PrincetonRutgers Census Data Project is no longer limited to its original mandate of providing the 1970 census information. It is now part of the overall data archive program which also incorporates the ICPSR, the Roper Center and the New Jersey State Data Center.
The New Jersey State Data Center

In 1977, with the advent of computer sophistication and the use of the 1970 census data in machine-readable form, the anticipation of large amounts of 1980 Census of Population and Housing data prompted the Census Bureau to develop plans for improved services to data users. These user services included access to census data in reports, computer tapes, microform, trainings, and consultation. The basic concept involved state-related organizations operating data delivery and user service facilities with guidance and assistance from the Census Bureau. One of the more important resources and services to be made available was the Federal Depository Library Program, through which many libraries receive Census Bureau publications at no charge. During the time of the 1970 census data, these services had fallen short of users needs. Not all processing centers offered training, not all states had census processing services, and not all locations offered consultation on technical matters. The State Data Center Program was proposed to close the gap in these user services. Rutgers University, as a primary participant of the New Jersey State Data Center, has fulfilled its obligation to provide these services.

\section{Continutng educatton...}

As part of the regular education series, conducted by the Rutgers CCIS, a general introductory seminar in data archives is given. In addition, special seminars are also available on an individual request basis. Many of these seminars have been held with the librarians to help idenify inquiries that we get in common, such as:

- a class for the reference librarians of the university emphasizing how to find out what is available by making use of different reference materials; - a session on exposure to increasingly sophisticated techniques of research and manipulation of our machine-rcadable data files as part of a library instruction program to enhance the research capabilities of undergraduate honor students; - a session on data archives for the librarians and the researchers on how to bridge the gap between the traditional library resource materials and the accompanying computer related material; - a seminar on how to direct prospective users through documentation, codebooks and accompanying printed material;

- a class for the doctoral students of the School of Communications, Information and Library Studies on how MRDFs will help the researchers.

In each case, the content of the lecture has been tailored to the interests and level of computer expertise of the group. These seminars enhance the interaction of the librarians and the computer center personnel because they often confer by phone when handling inquiries on the data archives. Hundreds of researchers have been 
assisted in this way. We began to realize that as the University Library utilizes the computer more and more for information retrieval, bibliographic searches, online cataloging and other functions, there will be an ever increasing working relationship between the Library and the CCIS.

ThE CURRENT STATUS OF OTHER PROJECTS...

It is to Rutgers good fortune that there were people within the two units who were keenly aware of the overlapping nature of our work, and willing to take on the extra work of communicating across departments. And so we went forward with a number of cooperative ventures in the early years. The Census project got us going, and even before our merger, the CCIS and Library worked out several projects together:

\section{ICPSR Codebook}

One of the first joint reference-related projects we arranged was for the Research Libraries to acquire additional copies of ICPSR Codebooks provided at the CCIS. Any time a codebook is ordered by CCIS, the ICPSR automatically sends a second copy to the Library; in the event that the codebook is only available on tape, the CCIS runs off a paper copy for the Library. Thus, the CCIS copies serve as a stable reference collection, and the Library copies increase availability - through both our extended hours of operation and because we circulate the codebooks. The circulation policy enables our faculty and students in three distant campuses to have ready access to the codebooks through our document delivery systems. Formerly, researchers from Camden and Newark had to travel to New Brunswick just to see the codebooks.

\section{Online end-user searching}

End-user online searching at Rutgers has been addressed mutually, as well. Programmers at CCIS developed a special communications sof tware for the Libraries' online end-user search service, entitled "kNightsearch." This software permits a masked password logon with an automatic self-destruct after one paid usage, and automatically terminates the session after the prescribed period of time. CCIS contributed not only their programming expertise, but also their Student Microcomputer Centers machinery as search terminals. The project was only partly successful: The Microcomputer Centers ultimately proved to be unsuitable environments for search; however, the software continues to be used in large science courses in the departments' own labs.

\section{Local mounting of databases}

As the Library further sought to enable patrons to gain access to online information, we began to investigate the mounting of databases locally. As an initial test project, for which the libraries invested seed money, we decided to mount ISI's Current Contents database, through the BRS OnSite program. Once again we turned to CCIS for their assistance in determining the technical needs, and for use of their mainframe. Having Current Contents available locally will allow researchers to search for titles directly instead of going through one of the commercial database vendors, like Dialog. Although both of CCIS's mainframes, an IBM compatible and the VAXcluster were very heavily used, it was determined by the CCIS systems staff that if we purchased an additional disk, we would be able to run Current Contents on the CMS operating system of the IBM. However, when we tested the system, with two groups of about fifteen librarians each, using a bench mark program developed by the librarians, we brought the CMS operating system almost to a halt.

By this time, we were already committed, by contract, to both BRS and ISI, and what we mainly had to show for all our efforts was a system with a response time that was too slow to be acceptable: to quote one member of the test team, "By the time you get a response, the Contents aren't Current anymore." Most unfortunately, we had lost the chance for a trial period, where we could have detected the problem before committing ourselves in a contract, because of the amount of time that it took to communicate up two separate administrative ladders the Library's and the CCIS's. This project serves as an example of how front-line efforts need coordinated support from administration in order to succeed.

\section{Online interface to data}

The Libraries have provided an online interface to CCIS. held polling data from the Roper Center since the introduction a few years ago of POLL, the Public Opinion Location Library. The Library offers searches of the database to identify appropriate surveys, and the CCIS provides data retrieval. Similarly, the Library can search the ICPSR Guide to Resources and Services for researchers online before they approach the CCIS for data. Furthermore, the library subscribes to and performs searches of some numeric databases produced by the U.S. government, and the state of New Jersey. For example, the New Jersey State Data Center/Business \& Industry Data Center Electronic Bulletin Board provides access to data prior to publication. Data is downloaded in either ASCII or Lotus 1-2-3 format for post-search manipulation. Again, we see a blurring of distinction between the kinds of information provided by the Libraries and the CCIS.

One important addition will be the availability of the government information on CDRom. Some of these data will be distributed to depository libraries by the Government Printing Office. Users can download the data and access with a commercial data base product. Again 
librarians and computer programmers will investigate and support this media.

\section{Student Microcomputer Project}

The creation of the Student Microcomputer Project was another result of sharing the resources of the two units. About five or six years ago, due to a tuition supplemental, different university governing bodies, which included student representatives, voted on buying microcomputers for non-classroom use. One of the student stipulations was to have them placed in the libraries so access would be during normal library hours and library resources would be available to them. Macintosh and AT\&T microcomputers were purchased and placed in four locations on the main campus. While the libraries agreed to provide precious physical space, the CCIS agreed to maintain the computers and give general support. As a resuit, this has proven to be one of the most successful projects that has greatly benefited students. The microcomputer areas are staffed by trained students; software and documentation are available on site. Each semester, seminars are held on operation of equipment, word processing, spreadsheets, databases and graphics. After the initial expenditure, the university provided funds in its ongoing budget to support the program.

\section{Software Information Center}

In almost any field, computers have become as essential as books, and in fact, in some instances, are even replacing books. To address this issue, the Software Information Center (S.I.C.) was established as a centralized forum for identification, evaluation, and sharing of software for the entire university. It also serves as a liaison to other consortia engaged in academic software development and exchange program. At the center, faculty and graduate students can preview various software packages; the range of courseware available is wide and holdings are constantly being expanded. The programs are available for both IBM and Macintosh microcomputers. In addition, assistance in using authoring programs is provided to help faculty develop their own courseware. The software collection is cataloged in the Integrated Rutgers Information System (IRIS) as a joint project with the University Libraries. IRIS is a computer database that contains the records for books and other material cataloged for the Rutgers Libraries and networked by the CCIS.

IN THE FUTURE ...

Networking

Networking, which is a scheme for connecting computers, is now on the horizon as the most important aspect of communicating between and among clients. We can reach most national and international networks but not all campus buildings. Most academic buildings on the campus where the main computer center is located are linked by a campus-wide broadband system. In addition, there are networks at each of the four remote computer locations. Now, with the merger of the libraries, academic computing and administrative computing, we are embarking on connecting all personnel electronically so that everyone will have access to an electronic mail box. This certainly will stimulate demand for computers. The logistics have to be worked out: significant upgrades will be required for existing systems; standards will have to be established to determine which system(s) will be used and how to handle capacity issues. We have a big job ahead of us. This can only be done through cooperation among those departments that provide information services to the university.

\section{National Center for Machine-Readable Texts in the Humanities}

Rutgers and Princeton Universities have received grants from the National Endowment for the Humanities, the Andrew W. Mellon Foundation, and the New Jersey Committee for the Humanities to jointly undertake the planning for a national center for machine-readable texts in the humanities. Project staff from Rutgers University includes the Associate University Librarian, an associate director from CCIS, and a member at large along with similar personnel from Princeton University and representatives from the Research Library Group.

During the course of the planning period the project staff will be investigating issues relating to the establishment of a cooperative center which will act as a central source of information on humanities data files and a selective source of data files themselves. The initial goals of the Center are to continue the on-going inventory of machine-readable texts; to catalog and disseminate this information; to acquire, preserve and distribute the textual data files which otherwise become generally unavailable; to distribute such data files in an appropriate manner; and to establish a resource center/referral point for information concerning other textual data. Other issues such as initial setup costs, administration of the project and the feasibility itself are also under investigation.

The Center plans to complement and enhance these collections by bringing bibliographic control to existing data files. To that end the project staff will be networking with other centers to establish appropriate means of collecting inventory data for the cataloging of archival holdings.

\section{Library Committee on Cataloging Machine-Readable Data files}

The CCIS Machine-Readable Data Files Committee was formed by the Technical and Automated Library Services to study how the cataloging of the data files housed at 
CCIS should proceed. The purpose of this study is to make the university aware of this collection, to strengthen the existing liaison between the libraries and the computer center, and to make a contribution in the area of computer file cataloging.

As yet, the MRDFs are not accessible to the Rutgers community via the libraries online catalog system neither are a large number of codebooks which accompany these files. Computer personnel have and will continue to work with the librarians on creating these catalog entries. Recommendations, as a result of this study, are that cataloging the data files and codes should be performed by librarians and administered by the Special Formats Cataloging section. It is just a matter of time before this project will begin.

\section{Problems and solutions}

Researchers need information, and do not particularly care where the information resides within the university. As is implied throughout this paper, some of the distinctions that the Library and CCIS make between our services tend now to be rather artificial, maintained more out of habit than by design. We need to rethink our roles from the point of view of the patron in need of information, to break from tradition when appropriate, and create information systems that are responsive to our constituency.

Across the years, the Libraries and CCIS have both committed staff, time, machinery, and hard cash to common causes. We have done a great deal, voluntarily, and together. Yet it must be said that in what we did, there were often problems; and moreover, there was so very much more left to be done.

\section{On the front lines...}

Yes we communicated. And yes, we did not. The problem, I believe, on the Library's part went to responsibility. While it is wonderful for individuals to voluntarily take on new and cooperative projects with another unit, the lack of formal responsibility led to things simply falling through the cracks. For example, when we began to collect a duplicate copy of the CCIS copy of JCPSR Codebooks, back-ordering was assumed, and the availability was publicized enthusiastically in Library and CCIS newsletters. So, we were very red-faced when a faculty member from our Newark campus, some thirty miles distant, responded to our much-publicized tout about availability of codebooks, and asked for the entire run of codebooks for the Annual Housing Survey. We were able to provide only codebooks from the past few years, as our subscription turned out not to be retroactive. The oversight was not caught because there was no-one who's job it was to catch it! And this is just one example of a small detail which nevertheless hinders information access to the researcher, and erodes our own credibility, as well.

One step that the Alexander Library, which is the research library for social sciences and humanities research at Rutgers, has taken to try to address this situation, is to designate a librarian to serve as coordinator for non-bibliographic database services. Besides working with the above-mentioned numeric databases, that person's natural function will be to work in concert with appropriate CCIS staff to see that researchers working along those "blurry" lines are guided along the most direct path to needed information.

\section{On the administrative end...}

Rutgers University's former president, the late Edward Bloustein, was a primary mover in the merger of the University's computing activities, articulating the need for coordination of the complex interrelationships between print information, electronic data resources and telecommunications. At a time when resources are limited and budgets strained, this plan of pooling resources, while perhaps not showing actual dollar savings, is intended to produce "intangible" savings via a streamlined and more efficient organization.

So, in order to coordinate the complicated, yet obviously converging, activities of the computing organizations on campus, a recent restructuring brings the Libraries and the computer services under one organizational umbrella. All units now report to the Vice President for Information Services at Rutgers, and University Librarian, Joanne Euster. President Bloustein also appointed Peter Graham, Associate University Librarian for Technical and Automated Services, to serve as associate Vice President for Information Services, in addition to continuing with his current responsibilities.

Joanne Euster explains the administrative rationale for restructuring in this way: "Economies of scale, as well as an apparent fading of the distinction between administrative and academic computing suggest that those functions should at least share some of the same pool of expertise and infrastructure. The goal should include minimizing duplicate input of information, ensuring the integrity of shared databases, being cost efficient, and making possible optimum individual control of one's own data access and utilization." Basically, this concept recognizes that the three affected units have tasks that are distinctive, and which are well-served within the unit, but that there are also centain aspects of the operations. For example, the academic and administrative sides of the computer share CPUs; the library and academic side share data; arid the administrative side provides its registrar's and personnel tapes to the library for its online patron file. 
Already, the administrative restructuring is having an effect on front-line services. Our plans to mount the Current Contents database have been resurrected thanks to the Associate Vice President for Information Services' decision to purchase a new mainframe computer that will fit our needs. The organizational changes provide new opportunities to expand the cooperative tradition of the Libraries and the CCIS, building on existing strengths, and exploring new ways of improving our services to Rutgers faculty and students. Our aim is to provide a "seamless" system of information services to data users.

IN CONCLUSION...

Computing services have changed. Library services have changed. Research methods have changed. Whether it becomes the responsibility of the library or the computer center to respond to change and meet new challenges is a moot issue. The clients continue to require information and increasingly this information is available in machinereadable form. Although the library and the computer center are independent of each other and deliver different forms and types of services, some of the information services overlap. The computing environment grows more complex each year and correspondingly, the responsibilities of our staff become more demanding. Because new technologies require us to be technically proficient in these areas, the merger of the libraries and the academic and administrative computing centers make sense. Because of the current budget restraints, these tasks must be clearly defined. Because of different perceptions of the type and level of service needed, there will be challenges in meshing these services. But with our long history of successful collaboration, the outcome of this new relationship is assured. And the faculty, students and staff will be the beneficiaries.

1 Presented jointly to the International Association for Social Science Information Service and Technology (IASSIST) Conference on "Numbers, Pictures, Words and Sounds: Priorities for the I990's" Poughkeepsie, New York on June 2, 1990. Linda Langschied, Information Services Librarian, Alexander Library, Rutgers University, New Brunswick, New Jersey, \& Gertrude J. Lewis, Deputy Associate Director, Center for Computer and Information Services, Rutgers University, Piscataway, New Jersey

\section{0 cartridges.}

For those interested in 3480 cartridges:

NTIS (PB8 233135) is selling for $\$ 12.95$ National Archives Technical Information Information Paper No. 4 "3480 Class Tape Certridge Drives and Archival Tape Storage: Technology Assessment Report."

\section{Call $703 / 487-4600$ or write to Document Sales NTIS, Springfield, VA 22161.}

This paper covers the "mechanical \& technological future of the systems" \& "provides valuable information to data center managers data librarians, and archivists, in fact to all who are concerned about the long-term storage of machine-readable data." 